\section{Search engines} increase online journal use more
than open access

The ability of internet search engines to find journal articles has considerably increased the readership of academic journals, a detailed analysis of the internet use of one particular research journal has found.

Introducing open access publishing achieved a smaller additional increase in journal use, the analysis showed.

Researchers at the Centre for Publishing at University College London used a deep log analysis, which collects "digital fingerprints" of users of specific internet sites, to track use of the online version of Nucleic Acids Research. They assessed use before and after the journal introduced an "author pays" open access publishing system, in which authors pay a fee to cover the cost of publishing their paper, which is then made available for free to readers.

The analysis found that access to the journal increased by $143 \%$ when its articles could be traced by search engines, from 132000 articles in early 2003 to 321000 in January 2005.

The introduction of open access publishing in January 2005 achieved a small further increase of about $19 \%$ in use of the journal. Most of this increase came from eastern European countries.

Susan Mayor London

\section{Hospital trusts fined because they cannot spare staff to work on IT}

NHS trusts are "being fined millions of pounds" because they are unable to meet agreements to assign staff to information technology (IT) contractors who are working on the national programme for IT, Richard Bacon, a Conservative MP and member of the Public Accounts Committee said this week.

The secondments were negotiated nationally as a way of ensuring that contractors understood NHS procedures, but many trusts have not complied, making themselves liable to penalty payments to contractors.

These payments add up to $£ 19 \mathrm{~m}(€ 28 \mathrm{~m} ; \$ 36 \mathrm{~m})$ in the south of England and $£ 6.9 \mathrm{~m}$ a year in the north west and west Midlands, ministers said in answers to parliamentary questions.

"At a time when hard pressed NHS trusts are having to make painful choices in order to reduce deficits, they are being forced to pay money they don't have and release staff they can't spare for something they don't want and which doesn't work," Mr Bacon said.

Michael Cross London

\section{Clarify role of} NHS market or patients may suffer, says King's Fund

The UK government must state unequivocally that it is committed to setting up a healthcare market, involving a range of different providers from the private and voluntary sectors. Otherwise patients could suffer as a result of reforms, said a report published this week by the King's Fund, an independent health charity.

The report, drawn up by a working group of senior executives from the NHS and the private and voluntary sectors, notes how the government has shifted towards a market system. Reforms have included payment by results (where patients have a choice of where they can have operations, and hospitals are paid per patient treated), semi-independent foundation hospitals, and a bigger role for the private sector.

Despite this introduction to a supplier market, however, which the report says has been achieved with "surprisingly little serious discussion," the government remains reluctant to fully commit to it.

Debashis Singh London

Designing the "New" NHS: Ideas to Make a Supplier Market in Health Care Work is available at www.kingsfund.org.uk.

\section{Fertility treatment regulator steps up warning about multiple births}

Caroline White London

The UK fertility treatment regulator has stepped up its warnings to couples seeking treatment about the risks of multiple births as a result of assisted conception techniques.

The move came last week as the Human Fertilisation and Embryology Authority published its new guide on treatment options for patients and healthcare professionals and released its latest set of figures on the live birth rate achieved at 85 UK licensed clinics.

The cumulative figures show that between April 2003 and March 2004 the live birth rate rose 1.2 percentage points on the previous year to $21.6 \%$. The increase was reflected across all age groups.

For women under the age of 35 years, and using their own eggs, the live birth rate rose to $28.2 \%$, an increase of just less than one percentage point.

But almost one in four of all assisted conception births$23.6 \%$, marginally down from $23.7 \%$ last year-resulted in either twins or triplets.

The new guide spells out much more clearly the risks of multiple births, in a bid to help people make appropriate choices and redefine what is deemed a "successful" outcome.

"If you are very desperate for a baby, and you have been trying for years, it may seem wonderful to have two or three come along at the same time," said Dame Suzi Leather, the chairwoman of the authority.

But the risk of death before birth and during the first week of life is four times greater with twins, and seven times greater with triplets, than it is with sin-

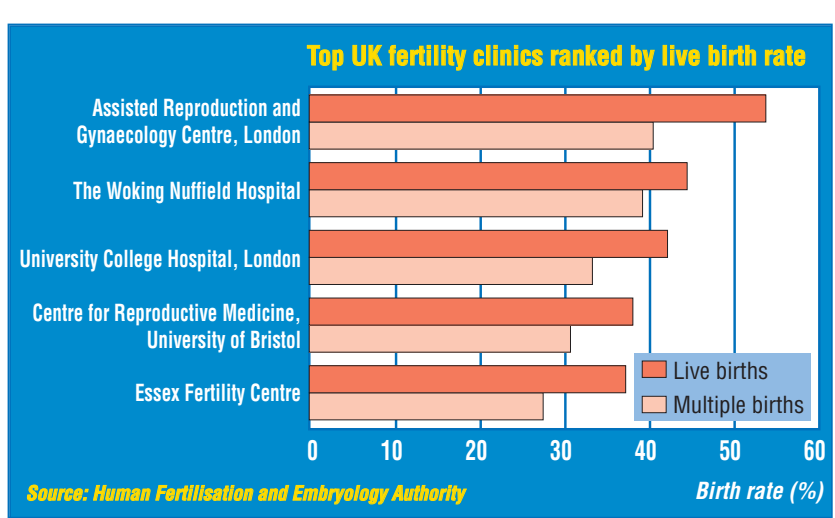

gleton births, and the chances of cerebral palsy are, respectively, five and 18 times higher, she said. "In the public discussions about the live birth rate, insufficient attention has been paid to the problem of multiple birth," she added.

Since April 2004, embryo transfer in UK licensed clinics has been limited to two for a woman younger than 40 years and three for a woman older than 40. But other European countries have adopted a policy of single embryo transfer in a bid to cut the risk of multiple births, and the authority is also considering this option, said Dame Suzi.

"We will need to look closely at the financial implications," she said, adding that couples might want to know they could have the back up of a frozen embryo transfer as well as a fresh embryo transfer.

The authority's new online facility, also launched last week, allows searches by postcode, age group, and treatment, and ranks clinics by live birth rates.

"Broadly speaking, there is little difference between most clinics in the UK," said Angela McNab, the authority's chief executive.

In the UK, about $25 \%$ of IVF treatments are funded by the NHS. The National Institute for Health and Clinical Excellence (NICE) guidelines suggest that couples should be offered up to 3 cycles of IVF on the NHS if the woman is aged 23-39 years and the couple has an identified cause for their infertility, or the woman has not conceived after 3 years. $\square$

The HFEA Guide to Infertility and the online search are available at www.hfea.gov.uk. 